\title{
Acute Gastroenteritis on Cruise Ships — United States, 2008-2014
}

\author{
Amy L. Freeland, $\mathrm{PhD}^{1}$; George H. Vaughan, Jr, $\mathrm{MPH}^{1}$; Shailendra N. Banerjee, $\mathrm{PhD}^{2}$
}

From 1990 to 2004, the reported rates of diarrheal disease (three or more loose stools or a greater than normal frequency in a 24-hour period) on cruise ships decreased $2.4 \%$, from 29.2 cases per 100,000 travel days to 28.5 cases $(1,2)$. Increased rates of acute gastroenteritis illness (diarrhea or vomiting that is associated with loose stools, bloody stools, abdominal cramps, headache, muscle aches, or fever) occurred in years that novel strains of norovirus, the most common etiologic agent in cruise ship outbreaks, emerged (3). To determine recent rates of acute gastroenteritis on cruise ships, CDC analyzed combined data for the period 2008-2014 that were submitted by cruise ships sailing in U.S. jurisdiction (defined as passenger vessels carrying $\geq 13$ passengers and within 15 days of arriving in the United States) (4). CDC also reviewed laboratory data to ascertain the causes of acute gastroenteritis outbreaks and examined trends over time. During the study period, the rates of acute gastroenteritis per 100,000 travel days decreased among passengers from 27.2 cases in 2008 to 22.3 in 2014 . Rates for crew members remained essentially unchanged (21.3 cases in 2008 and 21.6 in 2014). However, the rate of acute gastroenteritis was significantly higher in 2012 than in 2011 or 2013 for both passengers and crew members, likely related to the emergence of a novel strain of norovirus, GII.4 Sydney (5). During 2008-2014, a total of 133 cruise ship acute gastroenteritis outbreaks were reported, 95 (71\%) of which had specimens available for testing. Among these, $92(97 \%)$ were caused by norovirus, and among 80 norovirus specimens for which a genotype was identified, 59 (73.8\%) were GII. 4 strains. Cruise ship travelers experiencing diarrhea or vomiting should report to the ship medical center promptly so that symptoms can be assessed, proper treatment provided, and control measures implemented.

According to U.S. Foreign Quarantine regulations, passenger vessels, including cruise ships, are required to report the number of persons meeting the diarrheal disease case definition to U.S. authorities at CDC's Vessel Sanitation Program (VSP) 24-36 hours before arriving in the United States from a foreign port, even if there are zero cases (G). Additional reports are required if VSP's alert threshold is reached ( $\geq 2 \%$ cumulative attack rate* among either passenger or crew populations) or an outbreak occurs ( $\geq 3 \%$ cumulative attack rate among either passenger or crew populations); outbreaks of diarrheal disease are posted on VSP's website (http://www.cdc.gov/nceh/vsp). In 2001, VSP and the cruise industry expanded the diarrheal illness case definition to include acute gastroenteritis to more thoroughly detect and respond to illnesses that cause diarrhea and vomiting (4).

Data for 2008-2014 were analyzed per ship and voyage, using the most recently submitted report. Only voyages of 3-21 days in duration were included in the analysis, because cruise-associated illnesses associated with voyages of $<3$ days are more likely to manifest after disembarkation and, among voyages longer than 21 days (such as world cruises), report data often are incomplete. Voyages were included if they carried $\geq 100$ passengers, because small vessels can meet VSP's

* Cumulative attack rate refers to the attack rate for an entire voyage.

\section{INSIDE}

6 Sudden Deaths Among Oil and Gas Extraction Workers Resulting from Oxygen Deficiency and Inhalation of Hydrocarbon Gases and Vapors — United States, January 2010-March 2015

10 Notes from the Field: Subacute Sclerosing Panencephalitis Death — Oregon, 2015

12 Announcement

14 QuickStats

Continuing Education examination available at http://www.cdc.gov/mmwr/cme/conted_info.html\#weekly.

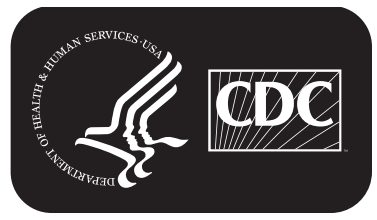

U.S. Department of Health and Human Services Centers for Disease Control and Prevention 
outbreak threshold with a single case; however, $99 \%$ of vessels submitting reports carried $>100$ passengers. Rates of acute gastroenteritis illness for both passenger and crew populations were calculated as the number of persons ill per 100,000 travel days and assessed for seasonality. Frequency of outbreaks per 1,000 voyages and the number of outbreaks per 10 million travel days also were calculated. The trend for each of these rates during 2008-2014 was assessed by fitting a linear regression line, and the trend for the actual number of outbreaks during this period was evaluated by Cochran-Armitage trend test. The rates per 100,000 travel days for 2011 and 2012, and for 2012 and 2013 were compared separately using a z-test. Similarly, the numbers of outbreaks per 1,000 voyages and per 10 million travel days for the same pairs of years were compared using a $\mathrm{t}$-test and z-test, respectively.

During 2008-2014, a total of 32,084 voyages required submission of a VSP report, ranging annually from 4,404 in 2012 to 4,808 in 2014 (Table); among these, 29,107 (90.7\%) were voyages of 3-21 days and included $>100$ passengers. Among a total of $73,599,005$ passengers who traveled during this period, 129,678 $(0.18 \%)$ cases of acute gastroenteritis were reported; and among $28,281,361$ crew members, ${ }^{\dagger} 43,132$ (0.15\%) cases were reported.

The rate of acute gastroenteritis per 100,000 travel days among passengers ranged from 20.9 in 2013 to 27.2 in 2008, and among crew members, from 19.3 in 2013 to 21.6 in 2014. The rate of illness demonstrated a decreasing but not

\footnotetext{
${ }^{\dagger}$ Represents the sum of crew members for each voyage reported to VSP.
}

TABLE. Acute gastroenteritis illness among passengers and crew members on cruise ships - United States, 2008-2014

\begin{tabular}{|c|c|c|c|c|c|c|c|}
\hline \multirow[b]{2}{*}{ Outbreak characteristics } & \multicolumn{7}{|c|}{ Year } \\
\hline & 2008 & 2009 & 2010 & 2011 & $2012^{*}$ & * 2013 & 2014 \\
\hline \multicolumn{8}{|l|}{ Voyages } \\
\hline Total no. of voyages & 4,694 & 4,506 & 4,627 & 4,621 & 4,404 & 4,424 & 4,808 \\
\hline $\begin{array}{l}\text { No. of voyages included } \\
\text { in analysis }\end{array}$ & 4,098 & 3,964 & 4,155 & 4,189 & 4,168 & 4,146 & 4,387 \\
\hline \multicolumn{8}{|l|}{ Passengers } \\
\hline $\begin{array}{l}\text { No. of acute gastroenteritis } \\
\text { outbreaks }\end{array}$ & 20 & 17 & 21 & 15 & $27^{\dagger}$ & 17 & 15 \\
\hline $\begin{array}{l}\text { No. of outbreaks per } \\
1,000 \text { voyages }\end{array}$ & 4.4 & 4.0 & 3.8 & 3.3 & $6.5^{\dagger}$ & 4.2 & 3.0 \\
\hline $\begin{array}{l}\text { No. of outbreaks per } \\
10 \text { million travel days }\end{array}$ & 2.9 & 2.5 & 2.7 & 1.9 & $3.3^{\dagger}$ & 2.1 & 1.8 \\
\hline $\begin{array}{l}\text { Rate of acute gastroenteritis } \\
\text { per } 100,000 \text { travel days }\end{array}$ & 27.2 & 22.6 & 26.4 & 22.7 & $25.8^{\dagger}$ & † 20.9 & 22.3 \\
\hline \multicolumn{8}{|l|}{ Crew members } \\
\hline $\begin{array}{l}\text { No. of acute gastroenteritis } \\
\text { outbreaks }\end{array}$ & 1 & 4 & 3 & 1 & 1 & 1 & 4 \\
\hline $\begin{array}{l}\text { No. of outbreaks per } \\
1,000 \text { voyages }\end{array}$ & 0.3 & 0.8 & 0.5 & 0.0 & 0.3 & 0.3 & 0.7 \\
\hline $\begin{array}{l}\text { No. of outbreaks per } \\
10 \text { million travel days }\end{array}$ & 0.4 & 1.5 & 1.0 & 0.3 & 0.3 & 0.3 & 1.2 \\
\hline $\begin{array}{l}\text { Rate of acute gastroenteritis } \\
\text { per } 100,000 \text { travel days }\end{array}$ & 21.3 & 19.7 & 20.8 & 19.6 & 20.3 & 19.3 & 21.6 \\
\hline
\end{tabular}

* A novel strain of norovirus (Gll.4 Sydney) emerged in 2012.

† Statistically significant increases: 2012 compared with 2011 and 2013.

statistically significant trend for either passengers $(p=0.16)$ or crew members $(p=0.96)$. However, the rates for passengers and crew members were significantly higher in 2012 than in 2011 (passengers: $\mathrm{p}<0.01$; crew members: $\mathrm{p}=0.02$ ) and 2013

The MMWR series of publications is published by the Center for Surveillance, Epidemiology, and Laboratory Services, Centers for Disease Control and Prevention (CDC), U.S. Department of Health and Human Services, Atlanta, GA 30329-4027.

Suggested citation: [Author names; first three, then et al., if more than six.] [Report title]. MMWR Morb Mortal Wkly Rep 2016;65:[inclusive page numbers]

\section{Centers for Disease Control and Prevention}

Thomas R. Frieden, MD, MPH, Director

Harold W. Jaffe, MD, MA, Associate Director for Science

Joanne Cono, MD, ScM, Director, Office of Science Quality

Chesley L. Richards, MD, MPH, Deputy Director for Public Health Scientific Services

Michael F. Iademarco, MD, MPH, Director, Center for Surveillance, Epidemiology, and Laboratory Services

\section{MMWR Editorial and Production Staff (Weekly)}

Sonja A. Rasmussen, MD, MS, Editor-in-Chief

Charlotte K. Kent, PhD, MPH, Executive Editor

Jacqueline Gindler, MD, Editor

Teresa F. Rutledge, Managing Editor

Douglas W. Weatherwax, Lead Technical Writer-Editor

Soumya Dunworth, PhD, Teresa M. Hood, MS, Technical Writer-Editors

Timothy F. Jones, MD, Chairman

Matthew L. Boulton, MD, MPH

Virginia A. Caine, MD

Katherine Lyon Daniel, $\mathrm{PhD}$

Jonathan E. Fielding, MD, MPH, MBA

David W. Fleming, MD

Martha F. Boyd, Lead Visual Information Specialist

Maureen A. Leahy, Julia C. Martinroe,

Stephen R. Spriggs, Moua Yang, Tong Yang, Visual Information Specialists

Quang M. Doan, MBA, Phyllis H. King,

Teresa C. Moreland, Terraye M. Starr,

Information Technology Specialists

MMWR Editorial Board

William E. Halperin, MD, DrPH, MPH

King K. Holmes, MD, PhD

Robin Ikeda, MD, MPH

Rima F. Khabbaz, MD

Phyllis Meadows, $\mathrm{PhD}, \mathrm{MSN}, \mathrm{RN}$

Jewel Mullen, MD, MPH, MPA
Jeff Niederdeppe, $\mathrm{PhD}$

Patricia Quinlisk, MD, MPH

Patrick L. Remington, MD, MPH

Carlos Roig, MS, MA

William L. Roper, MD, MPH

William Schaffner, MD 
(passengers: $\mathrm{p}<0.01$; crew members: $\mathrm{p}<0.01$ ). Monthly rates during 2008-2014 were higher during October-April (Figure 1).

The number of annual acute gastroenteritis outbreaks among passengers ranged from 15 in 2011 and 2014, to 27 in 2012 (3.0-6.5 outbreaks per 1,000 voyages), and among crew members, ranged from one in 2008, 2011, 2012, and 2013 to four in 2009 and 2014 ( $0-0.8$ outbreaks per 1,000 voyages) (Table); these differences exhibited a decreasing, although not statistically significant, linear trend (passengers: $p=0.89$; crew members: $p=0.98$ ). All but one of the crew outbreaks occurred concurrently with a passenger outbreak.

The number of outbreaks per 10 million travel days varied by year, ranging from 1.8 (2014) to 3.3 (2012) for passengers and from 0.3 (2013) to 1.5 (2009) for crew members. Although the raw number of outbreaks and rates per 10 million travel days decreased over time, the differences were not statistically significant (passengers: $\mathrm{p}=0.52$ and 0.29 , respectively; crew members: $p=0.96$ and 0.89 , respectively). However, the rate increase among passengers in 2012 was statistically significant compared with $2011(\mathrm{p}=0.04)$ but not compared with 2013 $(\mathrm{p}=0.06)$. The rate of acute gastroenteritis outbreaks among crew members in 2012 was not statistically significantly different compared with either $2011(\mathrm{p}=0.50)$ or $2013(\mathrm{p}=0.49)$.

Of the 29,107 voyages, 133 (0.5\%) had an outbreak. Among the 95 (71\%) outbreaks for which clinical specimens were available for testing, viruses were identified as the only causative agent in $87(92 \%)$ outbreaks, bacterial agents in three (3\%), both viral and bacterial agents in four (4\%), and viral and parasitic agents in one (1\%) outbreak. All of the viral gastroenteritis outbreaks were caused by norovirus, including four that were caused by more than one strain. The bacterial agents

FIGURE 1. Monthly rates of acute gastroenteritis cases on cruise ships, by patient type - Vessel Sanitation Program, United States, 2008-2014*

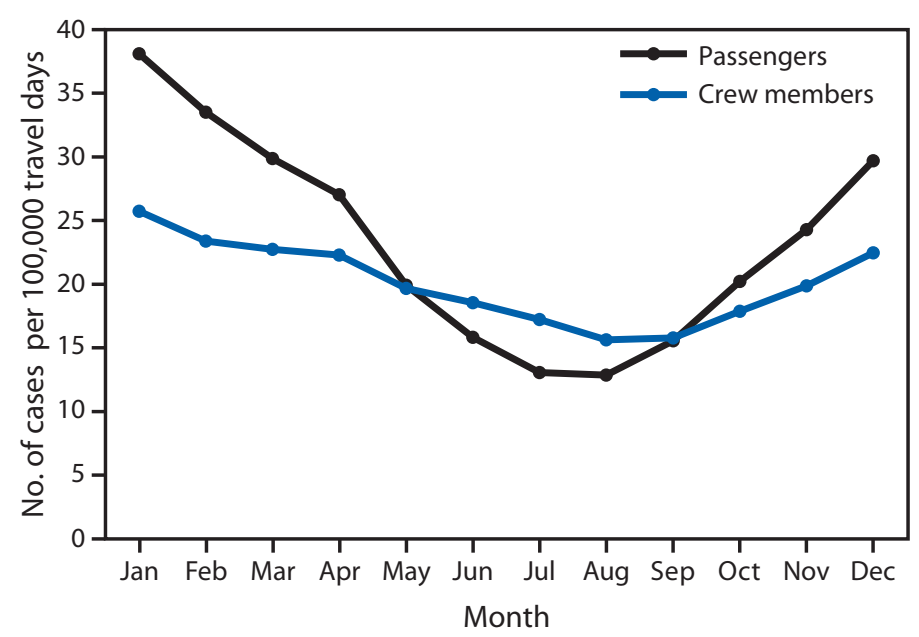

* Data combined for the period 2008-2014, and incidence calculated by month. implicated in the cruise ship outbreaks that affected passengers were enterotoxigenic Escherichia coli (six outbreaks), Shigella sonnei (one), and Campylobacter jejuni (one). One crew-only outbreak was caused by Clostridium perfringens. In addition, the parasite Cyclospora cayetanensis caused one outbreak (Figure 2). There were 129,678 passenger acute gastroenteritis cases during the study period. Only 19,273 (14.9\%) of these cases were part of an outbreak (133 outbreaks on 29,107 voyages), and $13,568(70.4 \%)$ cases were part of an outbreak in which the causative agent was laboratory-confirmed norovirus. Similarly, there were 43,132 crew member acute gastroenteritis cases of which only $1,984(4.6 \%)$ were part of an outbreak, and 1,343 $(67.7 \%)$ were part of an outbreak caused by norovirus.

\section{Discussion}

Approximately 73.5 million passengers sailed on voyages that required a VSP report during 2008-2014. During that period, 172,810 passengers and crew members met VSP's case definition for acute gastroenteritis, accounting for $0.18 \%$ of passengers and $0.15 \%$ of crew members (outbreak and nonoutbreak illnesses combined). Among cruise ship outbreaks with clinical specimens tested, $92 \%$ were caused by norovirus, with enterotoxigenic $E$. coli the second most common etiologic agent. Noroviruses are highly transmissible, can spread easily, especially in environments where persons live in close quarters such as long-term care facilities or dormitories, and can remain infectious on environmental surfaces for long periods of time $(7,8)$. Good hand hygiene is vital to preventing outbreaks of acute gastroenteritis, including on cruise ships. This is best accomplished by washing hands with soap and water because it allows for the mechanical removal of the virus from the hands

FIGURE 2. Number of acute gastroenteritis outbreaks* on cruise ships, by year and causative agent type - Vessel Sanitation Program, United States, 2008-2014

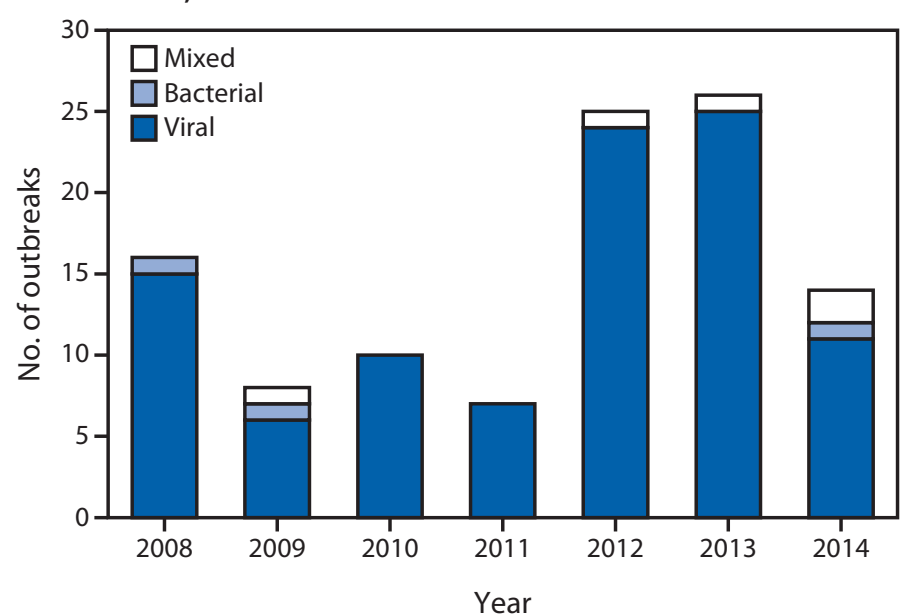

* Five acute gastroenteritis outbreaks on cruise ships had more than one causative agent. 
$(7,9)$. Alcohol-based hand sanitizer use alone has shown limited efficacy, but can be used in conjunction with handwashing with soap and water ( 7 ).

The enterotoxigenic E. coli outbreaks all occurred outside the United States on ships sailing back to the United States after visiting Central or South America. Overall, 14,911 passenger and crew acute gastroenteritis cases were associated with norovirus outbreaks during 2008-2014; these accounted for only $0.01 \%$ of the estimated 140 million norovirus cases in the United States during that period (3). Monthly rates of acute gastroenteritis on cruise ships were higher during OctoberApril for all years of the study period, with the highest rates of illness occurring during 2012, when a novel strain of norovirus was identified (GII.4 Sydney) (5). The overall seasonality and higher levels of illness in 2012 were similar to non-cruise ship U.S. acute gastroenteritis outbreak data, which showed higher rates of illness during November-April each year, and more norovirus illnesses during years when a novel strain of the virus was identified (3).

Rates of acute gastroenteritis and the number of acute gastroenteritis outbreaks were consistently lower among crew members than passengers, likely for multiple reasons. First, there are strict reporting and isolation requirements for crew members who experience acute gastroenteritis (4). Crew members who do not report symptoms of diarrhea or vomiting face discipline, which can include employment termination, because the risk they pose either through food handling or passenger interactions can lead to the spread of acute gastroenteritis. Additionally, because good hand hygiene is known to limit the spread of norovirus (9), hand washing stations are required at the entrances to all crew eating areas, and crew members are monitored in their use. Hand washing stations also are required to be located in food handling areas such that "no employee must walk more than 8 meters (26 feet) to reach a station" (10). As an additional food safety measure, crew members are not allowed bare hand contact with ready to eat foods (4). Finally, cruise lines have worked diligently to remove reporting barriers for passengers and crew members and encourage immediate reporting of any diarrhea or vomiting for medical assessment, treatment, and monitoring.

The findings in this report are subject to at least four limitations. First, voyages that did not include a foreign port or did not exceed VSP's alert or outbreak thresholds were not required to have a VSP report submitted, so the results might not reflect all voyages that occurred in U.S. waters. Second, VSP reports are only required when sailing from a foreign port to a U.S. port or when the cumulative incidence of acute gastroenteritis in either passenger or crew populations exceeds VSP's alert or outbreak thresholds; ships sailing between U.S. ports with a cumulative incidence lower than VSP's thresholds are not

\section{Summary \\ What is already known on this topic?}

From 1990 to 2004, the reported rates of diarrheal disease (three or more loose stools or a greater than normal amount in a 24-hour period) on cruise ships decreased $2.4 \%$, from 29.2 cases per 100,000 travel days to 28.5 cases. In 2001, the Vessel Sanitation Program and the cruise industry expanded the diarrheal illness case definition to include acute gastroenteritis (diarrhea, or vomiting that is associated with loose stools, bloody stools, abdominal cramps, headache, muscle aches, or fever). The most common causative agent has been norovirus.

What is added by this report?

From 2008 to 2014, the rate of acute gastroenteritis on cruise ships decreased among passengers from 27.2 cases per 100,000 travel days in 2008 to 22.3 in 2014, while the rate among crew members was essentially unchanged. The rate among both passengers and crew members was higher in 2012 compared with the preceding and following years, likely because of the emergence of a new norovirus strain. Among 73,599,005 passengers on cruise ships during 2008-2014, a total of 129,678 $(0.18 \%)$ cases of acute gastroenteritis were reported during outbreak and nonoutbreak voyages; among 28,281,361 crew members, 43,132 (0.15\%) cases were reported. Only a small proportion of those cases were part of a norovirus outbreak.

What are the implications for public health practice?

Cases of acute gastroenteritis illness on cruise ships are relatively infrequent. Norovirus, the most common causative agent of outbreaks, accounted for 14,911 cases among passengers and crew members during $2008-2014,0.01 \%$ of the estimated number of norovirus cases in the United States during the study period. To further reduce acute gastroenteritis on cruise ships, travelers should practice good hand hygiene, especially after using the toilet and before touching the face or eating; persons experiencing diarrhea or vomiting should promptly report their illness for proper assessment, treatment, and monitoring.

required to submit a report. Therefore, these data might not reflect the final case count at the end of the voyage. Third, case counts reported by ships and included in this study include only those persons who had symptoms while on the cruise ship and reported their symptoms to a crew member. The number of persons who experienced symptoms of acute gastroenteritis but did not report them is not known; thus, total case counts are likely underreported. Finally, in 2011, VSP included the phrase "or what is above normal for the individual" to the definition of diarrhea to align with federal regulation and the World Health Organization definition of diarrhea. This addition might have affected the number of persons who met the case definition because the definition now requires an assessment of "normal" rather than simply noting a frequency of $\geq 3$ episodes in 24 hours. 
The number and severity of cruise ship outbreaks of acute gastroenteritis varied during the study period, but were lower than rates reported during 2001-2004 (2). Collaborative efforts with the cruise industry have allowed VSP to provide more rapid support to cruise lines and ships experiencing higher than expected levels of acute gastroenteritis. Fewer and less severe outbreaks are likely the result of earlier detection of acute gastroenteritis, along with cruise industry efforts to identify and control outbreaks by developing and implementing required Outbreak Prevention and Response Plans (4), using processes and chemical disinfectants known to be effective against a norovirus surrogate and proactively seeking strategies to limit acute gastroenteritis spread, using the most currently available evidence.

\section{Acknowledgments}

Jaret Ames, Charles Otto, Aimee Treffiletti, Robert Quattlebaum, Larise Jackson, Stephanie Lawrence, Yolanda Allen, Vessel Sanitation Program, Division of Emergency and Environmental Health Services, National Center for Environmental Health, CDC; Jan Vinje, Nicole Gregoricus, Leslie Barclay, Sarah Shirley, National Calicivirus Laboratory, National Center for Immunization and Respiratory Diseases, CDC; Cheryl Bopp, Michele Parsons, Deborah Talkington, Enteric Diseases Laboratory Branch, Division of Foodborne, Waterborne, and Environmental Diseases, National Center for Emerging and Zoonotic Infectious Diseases, CDC; Barbara Herwaldt, Parasitic Diseases Branch, Division of Parasitic Diseases and Malaria, Center for Global Health, CDC; participating cruise lines.

\footnotetext{
${ }^{1}$ Vessel Sanitation Program, Division of Emergency and Environmental Health Services, National Center for Environmental Health, CDC; ${ }^{2}$ Division of Emergency and Environmental Health Services, National Center for Environmental Health, CDC.
}

Corresponding author: Amy L. Freeland, afreeland@cdc.gov, 770-488-7140.

\section{References}

1. Cramer EH, Gu DX, Durbin RE; Vessel Sanitation Program Environmental Health Inspection Team. Diarrheal disease on cruise ships, 1990-2000: the impact of environmental health programs. Am J Prev Med 2003;24:227-33. http://dx.doi.org/10.1016/ S0749-3797(02)00644-X.

2. Cramer EH, Blanton CJ, Blanton LH, et al.; Vessel Sanitation Program Environmental Health Inspection Team. Epidemiology of gastroenteritis on cruise ships, 2001-2004. Am J Prev Med 2006;30:252-7. http:// dx.doi.org/10.1016/j.amepre.2005.10.027.

3. Hall AJ, Lopman BA, Payne DC, et al. Norovirus disease in the United States. Emerg Infect Dis 2013;19:1198-205. http://dx.doi.org/10.3201/ eid1908.130465.

4. Vessel Sanitation Program. 2011 operations manual. Atlanta, GA: US Department of Health and Human Services, CDC, Vessel Sanitation Program; 2011. http://www.cdc.gov/nceh/vsp/operationsmanual/ opsmanual2011.pdf.

5. Leshem E, Wikswo M, Barclay L, et al. Effects and clinical significance of GII.4 Sydney norovirus, United States, 2012-2013. Emerg Infect Dis 2013;19:1231-8. http://dx.doi.org/10.3201/eid1908.130458.

6. Foreign quarantine. 42 C.F.R. Part 71. Washington DC: US Government Publishing Office; 2010. https://www.gpo.gov/fdsys/granule/CFR-2010title42-vol1/CFR-2010-title42-vol1-part71/content-detail.html.

7. Hall A, Vinje J, Lopman B, et al. Updated norovirus outbreak management and disease prevention guidelines. MMWR Recomm Rep 2011;60(No. RR-03).

8. Zheng DP, Widdowson MA, Glass RI, Vinjé J. Molecular epidemiology of genogroup II-genotype 4 noroviruses in the United States between 1994 and 2006. J Clin Microbiol 2010;48:168-77. http://dx.doi. org/10.1128/JCM.01622-09.

9. Wikswo ME, Cortes J, Hall AJ, et al. Disease transmission and passenger behaviors during a high morbidity norovirus outbreak on a cruise ship, January 2009. Clin Infect Dis 2011;52:1116-22. http://dx.doi. org/10.1093/cid/cir144.

10. Vessel Sanitation Program. 2011 construction guidelines. Atlanta, GA: US Department of Health and Human Services, CDC, Vessel Sanitation Program; 2011. http://www.cdc.gov/nceh/vsp/constructionguidelines/ constructionguidelines2011.pdf. 